\title{
Study of drag reduction by gas injection for power-law fluid flow in horizontal stratified and slug flow regimes
}

\author{
Jing-yu Xu*, Ying-xiang Wu, Hua Li, Jun Guo, Ying Chang \\ Institute of Mechanics, Chinese Academy of Sciences, No. 15 Beisihuanxi Road, Haidian District, Beijing 100190, China
}

\section{A R T I C L E I N F O}

\section{Article history:}

Received 23 April 2008

Received in revised form 25 June 2008

Accepted 1 July 2008

\section{Keywords:}

Drag reduction

Power-law fluid

Gas-liquid flow

Horizontal pipes

\begin{abstract}
A B S T R A C T
In this work, the drag reduction by gas injection for power-law fluid flow in stratified and slug flow regimes has been studied. Experiments were conducted to measure the pressure gradient within air/CMC solutions in a horizontal Plexiglas pipe that had a diameter of $50 \mathrm{~mm}$ and a length of $30 \mathrm{~m}$. The drag reduction ratio in stratified flow regime was predicted using the two-fluid model. The results showed that the drag reduction should occur over the large range of the liquid holdup when the flow behaviour index remained at the low value. Furthermore, for turbulent gas-laminar liquid stratified flow, the drag reduction by gas injection for Newtonian fluid was more effective than that for shear-shinning fluid, when the dimensionless liquid height remained in the area of high value. The pressure gradient model for a gas/Newtonian liquid slug flow was extended to liquids possessing the Ostwald-de Waele power law model. The proposed model was validated against 340 experimental data point over a wide range of operating conditions, fluid characteristics and pipe diameters. The dimensionless pressure drop predicted was well inside the $20 \%$ deviation region for most of the experimental data. These results substantiated the general validity of the model presented for gas/non-Newtonian two-phase slug flows.
\end{abstract}

(c) 2008 Elsevier B.V. All rights reserved.

\section{Introduction}

Many studies have been focused on the drag reduction phenomenon in the gas-liquid system in the last decades because of academic and industrial interests. Drag reduction can be formed by adding drag reduction agent (DRA) into a fluid, which would lead to a reduction in the two-phase pressure drop when the gas and liquid flow rates are fixed [1-5]. Another phenomenon that can be defined as the drag reduction is the injection of gas into nonNewtonian liquid, especially for pseudoplastic liquids, at a given liquid flow rate [6-14]. The present study focuses on the latter system by using the two-fluid modeling. The earliest study concerning this phenomenon was carried out by Ward and Dallavalle [6], who injected air into clay suspensions flowing in the laminar regime. The drag reduction phenomenon can be expressed by the dimensionless pressure drop:

$\Phi_{1}^{2}=\frac{\Delta P_{\mathrm{tp}}}{\Delta P_{\mathrm{sl}}}$

$\Phi_{\Delta}=1-\Phi_{1}^{2}$

\footnotetext{
* Corresponding author. Tel.: +8610 8254 4173; fax: +86 1062561284 .

E-mail addresses: xujingyu@imech.ac.cn, jinyu.xu@gmail.com (J.-y. Xu).
}

where $\Phi_{1}^{2}$ is the dimensionless pressure drop, $\Phi_{\Delta}$ is the drag reduction ratio, $\Delta P$ is the pressure drop and the subscripts tp, and sl refer to the two-phase and the superficial liquid phase, respectively. When the drag reduction occurred, $\Phi_{1}^{2}<1$ or $\Phi_{\Delta}>0$, which meant that two-phase pressure drop was smaller than that of the liquid phase flowing on its own at the same flow rate.

Most of traditional models predicted the drag reduction and liquid holdup in horizontal pipes based on the flow pattern. For stratified flow, the Heywood and Charles [6] extended the model of Taitel and Dukler [15] for gas/Newtonian liquid stratified flow to liquids obeying the Ostwald-de Waele power law model, and defined conditions for drag reduction of the liquid flow by the presence of the gas. According to Heywood and Charles's model, provided that liquid phase flows in a laminar, drag reduction should occur over the largest ranges of liquid and gas flow rates at the low $n$ values. However, they did not carry out the experiments to verify the model. Bishop and Deshpande [7] studied the power-law (shear thinning) liquid-gas uniform stratified flow using the model of Heywood and Charles. However, the two-phase drag reduction could not be obtained because there was a transition to semi-slug flow before the model criteria was reached.

Farooqi et al. [8] described the rheological behaviour of the suspensions as the Bingham plastic model and extended the Duker and Hubbard model [16] to predict the extent of drag reduction 


\begin{tabular}{|c|c|}
\hline \multicolumn{2}{|c|}{ Nomenclature } \\
\hline$A$ & cross-sectional area $\left(\mathrm{m}^{2}\right)$ \\
\hline$D$ & pipe diameter (m) \\
\hline$f$ & friction factor \\
\hline$g$ & acceleration of gravity $\left(\mathrm{m} / \mathrm{s}^{2}\right)$ \\
\hline G & the mass flux $\left(\mathrm{kg} /\left(\mathrm{m}^{2} \mathrm{~s}\right)\right)$ \\
\hline$h$ & fluid level (m) \\
\hline$l_{1}$ & liquid film zone of length (m) \\
\hline$l_{\mathrm{s}}$ & liquid slug zone of length (m) \\
\hline$l_{\mathrm{u}}$ & slug unit of length $(\mathrm{m})$ \\
\hline$m_{1}$ & fluid consistency coefficient ( $\mathrm{Pa} \mathrm{s}{ }^{n_{1}}$ ) \\
\hline$n_{1}$ & flow behaviour index \\
\hline$\Delta P$ & pressure drop $(\mathrm{Pa} / \mathrm{m})$ \\
\hline $\operatorname{Re}$ & Reynolds number \\
\hline$S$ & pipe perimeter $(\mathrm{m})$ \\
\hline$T$ & $\begin{array}{l}\text { ratio of the liquid slug zone of length to the slug unit } \\
\text { of length }\end{array}$ \\
\hline$u$ & mean velocity $(\mathrm{m} / \mathrm{s})$ \\
\hline$u_{\mathrm{d}}$ & drift velocity $(\mathrm{m} / \mathrm{s})$ \\
\hline$X^{2}$ & Lockhart-Martinelli parameter \\
\hline \multicolumn{2}{|c|}{ Greek symbols } \\
\hline$\alpha$ & liquid holdup \\
\hline$\varepsilon$ & absolute pipe roughness (m) \\
\hline$\mu_{\mathrm{eff}}$ & effective viscosity (PaS) \\
\hline$\rho$ & density $\left(\mathrm{kg} / \mathrm{m}^{3}\right)$ \\
\hline$\tau$ & shear stress $(\mathrm{Pa})$ \\
\hline$\Phi_{\Delta}$ & drag reduction ratio \\
\hline$\Phi_{1}^{2}$ & dimensionless pressure drop \\
\hline \multicolumn{2}{|c|}{ Subscripts } \\
\hline g & gas phase \\
\hline $\mathrm{i}$ & interface \\
\hline 1 & liquid phase \\
\hline $\mathrm{m}$ & $\begin{array}{l}\text { mixture velocities of the superficial gas and liquid } \\
\text { phases }\end{array}$ \\
\hline s & liquid slug \\
\hline sg & superficial gas phase \\
\hline sl & superficial liquid phase \\
\hline tp & two-phase \\
\hline $\mathrm{u}$ & slug unit \\
\hline
\end{tabular}

in the slug flow regime. The results showed that the drag reduction effect became progressively more marked as both the yield stress and plastic viscosity parameters increased with increasing suspension concentration. Afterward, Farooqi and Richardson [9] performed experiments on two-phase flow with both kaolin suspensions in water and water-glycerol mixtures. An empirical relationship between the minimum drag ratio and a dimensionless factor $\lambda_{c}$ was presented for the estimation of the maximum reduction in pressure drop at a given liquid velocity. By analyzing the same experimental data, Dziubinski [10] presented a general expression of drag ratio for two-phase pressure drop of gas/nonNewtonian fluid based on the concept of loss coefficient during the intermittent flow. In recent researches, Ruiz-Viera et al. [11] observed the drag reduction phenomenon during slug flow of a lubricating grease/air mixture using different geometries with both smooth and rough surfaces. The experimental data showed that drag reduction appeared to be dramatic by injecting relatively low flow rates of air, even more as liquid flow rate decreases. In addiction to these, $\mathrm{Xu}$ et al. [12] studied the co-current flow characteristics of air/power-law fluid systems in inclined smooth pipes using transparent tubes of 20,40 and $60 \mathrm{~mm}$ in diameter. In their works, the Heywood-Charles model was modified for horizontal flow to accommodate stratified flow in inclined smooth pipes. However, the drag reduction was not studied in detail.

In the chemical, oil and process industries, non-Newtonian liquids, especially pseudoplastic (power-law) liquids, are encountered frequently through pipelines over long distances. The pressure drop is one of the most important factors in hydraulic transport of gas-liquid flow. The effect of gas injection on the hydraulic transport of power-law fluid in a horizontal pipe is twofold. First, it forms a variety of flow patterns. Secondly, it may reduce or increase the pressure gradient in two-phase flow in comparison with the conventional hydraulic transport of single fluid, depending on the physical properties and input fluxes of the two phases, and the size of pipe. The reduction of the pressure gradient is of practical importance from an economic viewpoint since it may reduce the pumping energy of the fluid in long pipelines. Under some conditions, available quantities of gas with associated liquid could be transported without building a new pipeline or perhaps without increasing pump horsepower. For example, offshore production has necessitated transportation of both gas and liquid phases over long distances before separation. Conversely, study of the drag reduction is helpful to design the process equipments. The purpose of this study was to explore the effect of gas injection on the hydraulic transport of non-Newtonian power-law fluid in horizontal pipes. To this end, one-dimensional hydrodynamic models were formulated for predicting the holdup and the pressure drop for stratified and slug flow patterns. The proposed models were tested extensively against a large set of available experimental data in this work and others reported in the literature.

\section{Hydrodynamic modeling}

\subsection{Stratified flow in horizontal pipes}

Assuming a fully developed stratified flow, the integral forms of the momentum equations for the two fluids are written for the liquid and gas phase as follows (Fig. 1a):

$-A_{\mathrm{l}}\left(\frac{\mathrm{d} p}{\mathrm{~d} x}\right)_{\mathrm{tp}}-\tau_{\mathrm{l}} S_{\mathrm{l}}+\tau_{\mathrm{i}} S_{\mathrm{i}}+A_{\mathrm{l}} \rho_{\mathrm{l}} g \frac{\mathrm{d} h_{\mathrm{l}}}{\mathrm{d} x}-A \frac{\mathrm{d}\left(G_{\mathrm{l}} u_{\mathrm{l}}\right)}{\mathrm{d} x}=0$

$-A_{\mathrm{g}}\left(\frac{\mathrm{d} p}{\mathrm{~d} x}\right)_{\mathrm{tp}}-\tau_{\mathrm{g}} S_{\mathrm{g}}-\tau_{\mathrm{i}} S_{\mathrm{i}}+A_{\mathrm{g}} \rho_{\mathrm{g}} g \frac{\mathrm{d} h_{\mathrm{g}}}{\mathrm{d} x}-A \frac{\mathrm{d}\left(G_{\mathrm{g}} u_{\mathrm{g}}\right)}{\mathrm{d} x}=0$

where $A, h$ and $S$ are the cross-sectional area, the fluid level and the pipe perimeter, respectively. $G$ is the mass flux, $g$ is the acceleration due to gravity, $\tau$ is the shear stress and $\rho$ is the density. The subscripts tp, g, 1 and $i$ refer to the two-phase, gas phase, liquid phase and interface, respectively, eliminating the pressure drop by combining Eqs. (3) and (4), and ignoring the acceleration terms, yields a relation $F$ that can be used to calculate the liquid holdup, $\alpha_{1}$, by solving for the liquid height, $h_{1}$ :

$$
F=\tau_{\mathrm{g}} \frac{S_{\mathrm{g}}}{A_{\mathrm{g}}}-\tau_{\mathrm{l}} \frac{S_{\mathrm{l}}}{A_{\mathrm{l}}}+\tau_{\mathrm{i}} S_{\mathrm{i}}\left(\frac{1}{A_{\mathrm{l}}}+\frac{1}{A_{\mathrm{g}}}\right)-\Delta \rho g D \frac{\partial h_{\mathrm{l}} / D}{\partial \alpha_{1}} \frac{\partial \alpha_{1}}{\partial x}
$$

Provided that $F=0$ with $\partial \alpha_{1} / \partial x=0$, the equilibrium holdup can be obtained from the holdup relation (5). By designating the dimensionless quantities by a tilde $(\sim)$, a general dimensionless expression is given in the case of a uniform film thickness for strat- 


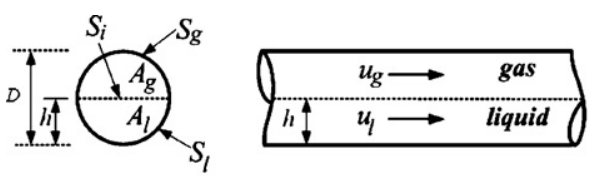

(a)

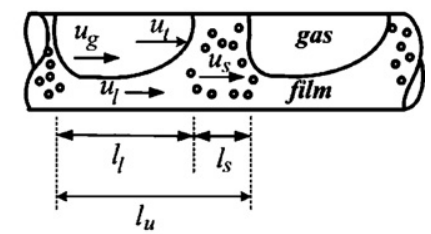

(b)

Fig. 1. Schematic description of (a) stratified and (b) slug flows.

ified flow:

$$
\begin{aligned}
& X^{2}\left(\frac{\tilde{S}_{\mathrm{l}} \tilde{u}_{1}^{n_{1}}}{\tilde{A}_{\mathrm{l}} \tilde{D}_{1}^{n_{1}}}\right)-\frac{\tilde{S}_{\mathrm{g}} \tilde{u}_{\mathrm{g}}^{2-m}}{\tilde{A}_{\mathrm{g}} \tilde{D}_{\mathrm{g}}^{m}}-\frac{f_{\mathrm{i}}}{f_{\mathrm{g}}} \frac{\tilde{u}_{\mathrm{g}}^{2-m}}{\tilde{D}_{\mathrm{g}}^{m}}\left(1-q \frac{\tilde{u}_{\mathrm{l}}}{\tilde{u}_{\mathrm{g}}}\right)\left|1-q \frac{\tilde{u}_{\mathrm{l}}}{\tilde{u}_{\mathrm{g}}}\right| \\
& \left(\frac{\tilde{S}_{\mathrm{i}}}{\tilde{A}_{\mathrm{l}}}+\frac{\tilde{S}_{\mathrm{i}}}{\tilde{A}_{\mathrm{g}}}\right)=0
\end{aligned}
$$

where $q=u_{\mathrm{sl}} / u_{\mathrm{sg}} ; \quad \tilde{u}_{\mathrm{l}}=u_{\mathrm{l}} / u_{\mathrm{sl}}$ and $\tilde{u}_{\mathrm{g}}=u_{\mathrm{g}} / u_{\mathrm{sg}} ; \quad \tilde{D}_{\mathrm{l}}=D_{\mathrm{l}} / D$ and $\tilde{D}_{\mathrm{g}}=D_{\mathrm{g}} / D ; \quad \tilde{S}_{\mathrm{l}}=S_{\mathrm{l}} / D, \quad \tilde{S}_{\mathrm{g}}=S_{\mathrm{g}} / D$ and $\tilde{S}_{\mathrm{i}}=S_{\mathrm{i}} / D ; \quad \tilde{A}_{\mathrm{l}}=A_{\mathrm{l}} / D^{2}$ and $\tilde{A}_{\mathrm{g}}=A_{\mathrm{g}} / D^{2}$. The dimensionless variables in Eq. (6) are functions of the dimensionless liquid height, $\tilde{h}_{\mathrm{l}}=h_{\mathrm{l}} / D . X^{2}$ is the Lockhart-Martinelli [17] parameter defined by

$X^{2}=\frac{\Delta P_{\text {sl }}}{\Delta P_{\text {sg }}}$

The Fanning friction factors are defined by

$\tau_{\mathrm{g}}=f_{\mathrm{g}} \frac{\rho_{\mathrm{g}} u_{\mathrm{g}}^{2}}{2} ; \quad \tau_{\mathrm{l}}=f_{\mathrm{l}} \frac{\rho_{\mathrm{l}} u_{\mathrm{l}}^{2}}{2} ; \quad \tau_{\mathrm{i}}=f_{\mathrm{i}} \frac{\rho_{\mathrm{g}}\left(u_{\mathrm{g}}-u_{\mathrm{l}}\right)\left|u_{\mathrm{g}}-u_{\mathrm{l}}\right|}{2}$

The liquid and gas friction factors in a smooth pipe can be approximated by

$f_{\mathrm{l}}=C_{\mathrm{l}} R e_{\mathrm{l}}^{-n} ; \quad f_{\mathrm{g}}=C_{\mathrm{g}} R e_{\mathrm{g}}^{-m}$

where $C_{1}=C_{g}=0.079, n=m=0.25$ for turbulent flow, and $C_{1}=C_{g}=16$, $n=m=1$ for laminar flow. The Reynolds number for the gas phase as Newtonian fluid is defined by

$\operatorname{Re}_{\mathrm{g}}=\frac{D_{\mathrm{g}} u_{\mathrm{g}} \rho_{\mathrm{g}}}{\mu_{\mathrm{g}}}$

For non-Newtonian liquid phase the rheological behaviour obeys the commonly encountered Ostwald-de Waele power law model. The appropriate Reynolds number is defined as

$\operatorname{Re}_{\mathrm{MR}}=\frac{D_{1}^{n_{1}} u_{1}^{2-n_{1}} \rho_{1}}{8^{n_{1}-1} K}, \quad K=m_{1}\left(\frac{1+3 n_{1}}{4 n_{1}}\right)^{n_{1}}$

Once a solution has been obtained for $\tilde{h}_{\mathrm{l}}$ by Eq. (6), the liquid holdup and the dimensionless pressure drop can be given respectively as

$\alpha=1-\frac{1}{\pi}\left[\cos ^{-1}\left(2 \tilde{h}_{1}-1\right)-\left(2 \tilde{h}_{1}-1\right) \sqrt{1-\left(2 \tilde{h}_{1}-1\right)^{2}}\right]$

$\Phi_{1}^{2}=\frac{1}{\pi}\left(\tilde{S}_{1} \frac{\tilde{u}_{1}^{n_{1}}}{\tilde{D}_{1}^{n_{1}}}+\tilde{S}_{\mathrm{g}} \frac{1}{X^{2}} \frac{\tilde{u}_{\mathrm{g}}^{2-m}}{\tilde{D}_{\mathrm{g}}^{m}}\right)$

Provided $f_{\mathrm{i}}=f_{\mathrm{G}}$ [15], using Eq. (6) to eliminate $X^{2}$ in Eq. (13) yields:

$\Phi_{1}^{2}=K^{\prime} \frac{\tilde{u}_{1}^{n_{1}}}{\tilde{D}_{1}^{n_{1}}}$ where

$$
\begin{aligned}
K^{\prime} & =\frac{\tilde{S}_{\mathrm{l}}}{\pi} \\
& \times\left\{1+\frac{\tilde{S}_{\mathrm{g}} / \tilde{A}_{\mathrm{l}}}{\left[\left(\tilde{S}_{\mathrm{g}} / \tilde{A}_{\mathrm{g}}\right)+\left(1-q\left(\tilde{u}_{\mathrm{l}} / \tilde{u}_{\mathrm{g}}\right)\right)\left|1-q\left(\tilde{u}_{\mathrm{l}} / \tilde{u}_{\mathrm{g}}\right)\right|\left(\left(\tilde{S}_{\mathrm{i}} / \tilde{A}_{\mathrm{l}}\right)+\left(\tilde{S}_{\mathrm{i}} / \tilde{A}_{\mathrm{g}}\right)\right)\right]}\right\}
\end{aligned}
$$

where $\Phi_{1}^{2}$ is only function of the dimensionless liquid height $\left(\tilde{h}_{1}\right)$ if $q$ is known as the ratio of liquid flow rate to gas flow rate.

\subsection{Slug flow in horizontal pipes}

In the slug unit of length, $l_{\mathrm{u}}$, consists of two separate sections: the liquid slug zone of length $l_{\mathrm{s}}$ and the film zone of length $l_{\mathrm{l}}$ (Fig. $1 \mathrm{~b}$ ). Assuming that the film contains no entrained gas bubbles and a uniform film along the film zones, the average pressure gradient in a slug unit is obtained by performing a momentum balance over a global control volume of the slug unit:

$$
\left(\frac{\mathrm{d} p}{\mathrm{~d} x}\right)_{\mathrm{tp}}=2 \frac{f_{\mathrm{s}}}{D} \rho_{\mathrm{s}} u_{\mathrm{s}}^{2} \frac{l_{\mathrm{s}}}{l_{\mathrm{u}}}+\frac{4}{\pi D^{2}} \frac{l_{\mathrm{l}}}{l_{\mathrm{u}}}\left(\frac{f_{\mathrm{g}} \rho_{\mathrm{g}} u_{\mathrm{g}}^{2}}{2} S_{\mathrm{g}}+\frac{f_{\mathrm{l}} \rho_{\mathrm{l}} u_{\mathrm{l}}^{2}}{2} S_{\mathrm{l}}\right)
$$

where $\rho_{\mathrm{S}}=\left(1-\alpha_{\mathrm{S}}\right) \rho_{\mathrm{g}}+\alpha_{\mathrm{s}} \rho_{\mathrm{l}}$ is the average density within the liquid slug. $\alpha_{\mathrm{s}}$ refers the liquid holdup in the liquid slug. For nonNewtonian materials in smooth pipes, $f_{\mathrm{s}}$ is the liquid slug friction factor, which is calculated in the same way as for $f_{1}$ with the liquid slug Reynolds number given by

$R e_{\mathrm{s}}=\frac{D^{n_{1}} u_{\mathrm{s}}^{2-n_{1}} \rho_{\mathrm{s}}}{8^{n_{1}-1} K}$

In addition to the above parameters the turbulent friction factors $f_{1}, f_{\mathrm{g}}$ and $f_{\mathrm{s}}$ in Eq. (16) should be specified in a commercial pipe. The following relations have been used [18]:

$f_{k}=0.001375\left[1+\left(2 \times 10^{4} \frac{\varepsilon}{D_{k}}+\frac{10^{6}}{R e_{k}}\right)^{1 / 3}\right]$

where $k$ represents liquid phase, gas phase or liquid slug, and $\varepsilon$ is the absolute pipe roughness.

The liquid and gas mass balances over the slug unit yield:

$u_{\mathrm{sl}}=\frac{1}{l_{\mathrm{u}}}\left(l_{\mathrm{s}} u_{\mathrm{s}} \alpha_{\mathrm{s}}+l_{\mathrm{l}} u_{1} \alpha_{1}\right)$

$u_{\mathrm{sg}}=\frac{1}{l_{\mathrm{u}}}\left[l_{\mathrm{s}} u_{\mathrm{s}}\left(1-\alpha_{\mathrm{s}}\right)+l_{\mathrm{l}} u_{\mathrm{g}}\left(1-\alpha_{\mathrm{l}}\right)\right]$

According to Taitel and Barnea [18], the aerated liquid slug velocity, $u_{\mathrm{m}}$ is evaluated by

$u_{\mathrm{m}}=u_{\mathrm{sl}}+u_{\mathrm{sg}}$

where $u_{\mathrm{m}}$ is the mixture velocities of the superficial gas and liquid phase. A gas mass balance relative to a coordinate system that 
moves with a translation velocity, $u_{\mathrm{t}}$ yields:

$\left(1-\alpha_{\mathrm{l}}\right)\left(u_{\mathrm{t}}-u_{\mathrm{g}}\right)=\left(1-\alpha_{\mathrm{s}}\right)\left(u_{\mathrm{t}}-u_{\mathrm{m}}\right), \quad u_{\mathrm{t}}=c u_{\mathrm{m}}+u_{\mathrm{d}}$

where $c$ is related to the liquid velocity profile ahead of the elongated bubble, $c=1.2$ for turbulent flow and $c=2.0$ for laminar flow. $u_{\mathrm{d}}$ is the drift velocity, following Bendiksen's proposition [19]:

$u_{\mathrm{d}}=0.54 \sqrt{g D}$

The liquid holdup, $\alpha$, over a slug unit is

$\alpha=\alpha_{\mathrm{s}}-\frac{1}{u_{\mathrm{t}}}\left(u_{\mathrm{sg}}-\left(1-\alpha_{\mathrm{s}}\right) u_{\mathrm{m}}\right)$

where $\alpha_{\mathrm{s}}=\frac{1}{1+\left(u_{\mathrm{m}} / 8.66\right)^{1.39}}[20]$.

Considering Eqs. (19) and (20), the ratio of the liquid slug zone of length to the slug unit of length is expressed by

$T=\frac{l_{\mathrm{s}}}{l_{\mathrm{u}}}=\frac{u_{\mathrm{sl}}-u_{\mathrm{l}} \alpha_{1}}{u_{\mathrm{s}} \alpha_{\mathrm{s}}-u_{1} \alpha_{1}}$

Eqs. (5), (8), (9) or (18-20) and (22) result in a set of six simultaneous equations that contain six unknowns. Thus, the average pressure gradient in a slug unit can be solved analytically by substituting the equations to Eq. (16). Then the dimensionless pressure drop can be expressed in a slug flow:

$\Phi_{1}^{2}=\Phi_{\mathrm{s}}+\Phi_{\mathrm{f}}$

where

$\Phi_{\mathrm{s}}=\frac{2\left(f_{\mathrm{s}} / D\right) \rho_{\mathrm{s}} u_{\mathrm{s}}^{2}\left(l_{\mathrm{s}} / l_{\mathrm{u}}\right)}{2\left(f_{\mathrm{sl}} / D\right) \rho_{\mathrm{sl}} u_{\mathrm{sl}}^{2}}$,

$\Phi_{\mathrm{f}}=\frac{\left(4 / \pi D^{2}\right)\left(l_{\mathrm{l}} / l_{\mathrm{u}}\right)\left(\left(f_{\mathrm{g}} \rho_{\mathrm{g}} u_{\mathrm{g}}^{2} / 2 S_{\mathrm{g}}\right)+\left(f_{\mathrm{l}} \rho_{\mathrm{l}} u_{\mathrm{l}}^{2} / 2 S_{\mathrm{l}}\right)\right)}{2\left(f_{\mathrm{sl}} / D\right) \rho_{\mathrm{sl}} u_{\mathrm{sl}}^{2}}$

where $\Phi_{\mathrm{S}}$ and $\Phi_{\mathrm{f}}$ are the dimensionless pressure drop in the liquid slug and in the film zone, respectively.

\section{Description of the experiments}

The experimental investigation in this work was conducted in the setup shown in Fig. 2. Air came from a compressor pump via gas mass flow meter. Polymer solutions used as the liquid phases were conveyed from liquid phase tank into the pipeline. Liquid phase and gas phase were fed into the pipeline via a T-junction. The volumetric flow rates of all phases could be regulated independently and were measured by thermal mass flow meter for air phase and electromagnetic flow meter for polymer solutions. The multiphase flow pipeline was manufactured of perspex tubing with an internal diameter of $50 \mathrm{~mm}$ through which the flow could be observed. The total length of this pipeline between the entrance and the separation unit was approximately $30 \mathrm{~m}$. The pipeline consists of two horizontal legs with a leg length of 10 and $14 \mathrm{~m}$, respectively, connected by a horizontal U-turn. The sampling frequency of the pressure was $500 \mathrm{~Hz}$ and a total of 60,000 samples, which corresponded to 2 min sampling time, were collected. The liquid holdup was measured using two rapid closing valves, which were full opening ball valves with inside diameters equal to the inside diameter of the pipe so that the flow was not disturbed by passing through the open valves. After the valves were closed, the amount of liquid trapped between the valves was measured to determine the holdup. Following the propositions of Nydal et al. [21] and Andreussi et al. [22], the average slug unit of length was approximately equal to $40 \mathrm{D}$ when superficial gas velocity was less than $6 \mathrm{~m} / \mathrm{s}$. The diameter of pipe on this loop was $0.05 \mathrm{~m}$. Therefore, the distance between the valves was fixed on $2 \mathrm{~m}$. Furthermore, the operation time of two rapid closing valves was $0.5 \mathrm{~s}$. This provided sufficient short time to measure accurately the holdup and the fluctuation of mean value among the three sets of data was around $5 \%$. Flow patterns were recorded using a high-speed video camera, and the flow patterns for each test condition were recorded and could be observed later in slow motion. A total of 180 experimental tests had been conducted for the following conditions: superficial liquid velocity from 0 to $1.42 \mathrm{~m} / \mathrm{s}$, superficial gas velocity from 0 to $2.59 \mathrm{~m} / \mathrm{s}$ and input liquid phase cuts from 0 to $100 \%$.

Tap water was used as Newtonian liquid phase and four different concentrations CMC (carboxymethyl cellulose) solutions used as non-Newtonian fluid. Solutions were prepared by adding small quantities of dry polymer powders accompanied by gentle stirring to prevent the formation of lumps. The density of each solution was measured using a constant volume density bottle. The CMC rheology experiments are measured with a ThermoHaake RS300 rheometer. A double gap cylinder sensor system with an outside gap of $0.30 \mathrm{~mm}$ and an inside gap of $0.25 \mathrm{~mm}$ was used. As expected, CMC solutions in this study were shear-thinning fluids whose rheology can be described by Ostwald-de Waele power law model.

$\tau=m_{1}(\dot{\gamma})^{n_{1}}$

where $\dot{\gamma}$ is the shear rate, $m_{1}$ and $n_{1}$ are two empirical curve-fitting parameter and are known as the fluid consistency coefficient and the flow behaviour index, respectively. The values of $m_{1}, n_{1}$ and other properties of the CMC solutions are given in Table 1 .
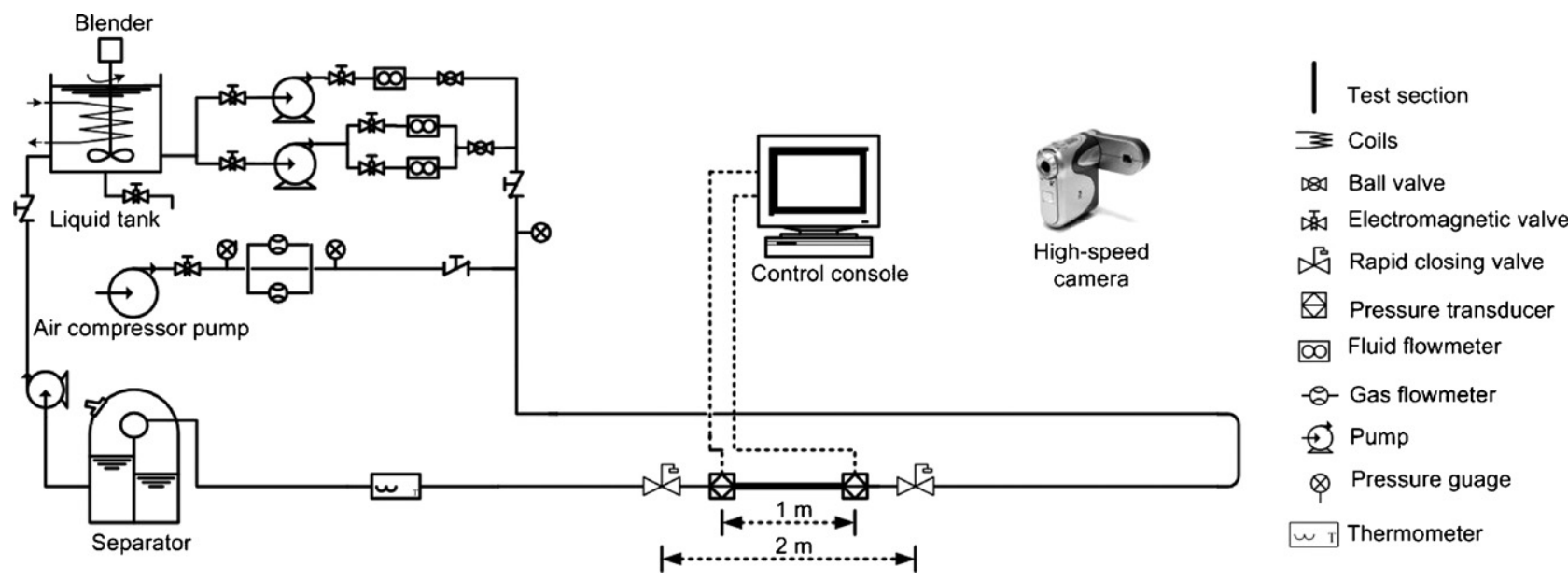

Fig. 2. Schematic of the test facility. 
Table 1

Physical properties of the liquid phase measured at $20^{\circ} \mathrm{C}$ and $0.1 \mathrm{MPa}$

\begin{tabular}{|c|c|c|c|c|}
\hline Liquid phase & Concentration $\left(\mathrm{kg} / \mathrm{m}^{3}\right)$ & Density, $\rho\left(\mathrm{kg} / \mathrm{m}^{3}\right)$ & Fluid consistency coefficient, $m_{1}$ ( $\mathrm{Pa} \mathrm{s}^{n_{1}}$ ) & Flow behaviour index, $n_{1}$ \\
\hline Water & - & 997.0 & 0.001 & 1.000 \\
\hline CMC -1 solution & 0.5 & 999.9 & 0.034 & 0.952 \\
\hline CMC-2 solution & 2.0 & 1000.0 & 0.407 & 0.765 \\
\hline CMC -3 solution & 2.5 & 1000.2 & 1.365 & 0.595 \\
\hline CMC -4 solution & 3.5 & 1000.4 & 2.434 & 0.535 \\
\hline
\end{tabular}

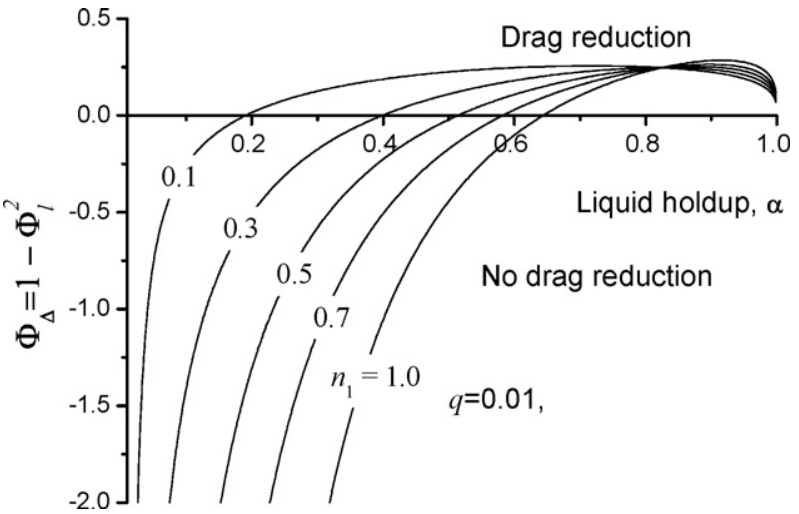

Fig. 3. The effect of the flow behaviour index $\left(n_{1}\right)$ on the drag reduction ratio, $\Phi_{\Delta}^{2}$, in horizontal stratified flow.

\section{Results and discussion}

\subsection{Drag reduction in stratified flow}

The drag reduction ratio as predicted by introducing the Eq. (13) to Eq. (2) is presented in Fig. 3 for various $n_{1}$ values. It can be seen that over the range $0.1<\alpha<0.8 \Phi_{\Delta}$ increases as $n_{1}$ is decreased from 1.0 to 0.1 , but for a high value of $\alpha$ the reverse is true. The drag reduction occurs over the greatest range of $\alpha$ at the lowest $n_{1}$ values. However, Fig. 3 also reveals the interesting result that the maximum drag reduction ratio occurs at the highest $n_{1}$ value. Thus, the drag reduction by gas injection for Newtonian fluid in a laminar flow should be more effective than that for shear-shinning fluid, when the dimensionless liquid height remains in the area of high value.

Provided that $q$ and $n$ are known, the effect of variation in $\tilde{h}$ on the drag reduction ratio can be calculated by using the Eq. (13). When the drag reduction ratio reach the maximum value, $\tilde{h}$ may be obtained by the differentiation of Eq. (2) as

$\frac{\partial \Phi_{\Delta}}{\partial \tilde{h}}=\frac{\partial\left(1-\Phi_{1}^{2}\right)}{\partial \tilde{h}}=0$

where $\Phi_{\Delta}$ is only the function of $\tilde{h}$. Thus, the maximum drag reduction ratio can be obtained by the Eq. (29). Values of important variables in Fig. 3 are presented in Table 2 when the maximum drag reduction takes place.

Table 2

Values of important variables in Fig. 3 under constant $q=0.01$

\begin{tabular}{llll}
\hline $\begin{array}{l}\text { Flow behaviour } \\
\text { index, } n_{1}\end{array}$ & $\begin{array}{l}\text { Maximum drag } \\
\text { reduction, } \Phi_{\Delta} \\
(\%)\end{array}$ & $\begin{array}{l}\text { Dimensionless } \\
\text { liquid height, } \tilde{h}\end{array}$ & Liquid holdup, $\alpha$ \\
\hline 0.1 & 25.7 & 0.675 & 0.718 \\
0.3 & 24.5 & 0.774 & 0.830 \\
0.5 & 25.4 & 0.817 & 0.875 \\
0.7 & 26.5 & 0.840 & 0.897 \\
1 & 28.6 & 0.861 & 0.916 \\
\hline
\end{tabular}

The drag reduction ratio, $\Phi_{\Delta}$, as a function of the ratio of liquid flow rate to gas flow rate $(q)$ is plotted in Fig. 4. For a given $n_{1}, \Phi_{\Delta}$ decreases slightly as $q$ is increased. The curve is approximatively linear. It can be seen from Fig. 4 that, for a high value $\tilde{h}$, both the $q$ and the $n_{1}$ have a minimal effect on $\Phi_{\Delta}$.

Furthermore, the influence of $n$ on $\Phi_{\Delta}$ may be also given by the differentiation of Eq. (2):

$\frac{\partial \Phi_{\Delta}}{\partial n}=-K^{\prime} \log \left(\frac{\tilde{u}_{1}}{\tilde{D}_{\mathrm{g}}}\right) \frac{\tilde{u}_{1}^{n_{1}}}{\tilde{D}_{\mathrm{g}}^{n_{1}+1}}$

In previous works, Heywood and Charles [6] assumed that the average gas velocity is always larger than the average liquid velocity and $\tau_{\mathrm{i}}$ is in the positive $x$ direction for the liquid and in the negative direction for the gas. Thus, $K^{\prime}$ can be simplified as

$K^{\prime}=\frac{\tilde{S}_{\mathrm{g}}+\tilde{S}_{\mathrm{i}}}{\tilde{S}_{\mathrm{i}}+(\pi / 4)\left(\tilde{S}_{\mathrm{i}} / \tilde{A}_{\mathrm{l}}\right)}>0$

However, in the present study, this postulate condition is not adopted because in practice the gas velocity might be larger or smaller than the liquid velocity depending on input conditions. Fig. 5 shows the comparison results between the theoretical method in this work and the Heywood and Charles model for predicting the effects of $K^{\prime}$ on the liquid holdup. In Fig. 5a, when $q=0.01$, the values of $K^{\prime}$ calculated by Eq. (31) is close to those obtained by Eq. (15). However, when $q$ is increased, the considerable differences can be found in Fig. $5 b$ and c. There is an opposite direction jump in the curve predicted by Eq. (15). The reasons for this truncation point may be explained by the fact that the direction of $\tau_{\mathrm{i}}$ depends on the value of $\left(1-q \tilde{u}_{1} / \tilde{u}_{\mathrm{g}}\right)$. When the direction of $\tau_{\mathrm{i}}$ is changed, the values of $K^{\prime}$ will jump from negative to positive. Such behaviour can occur in the transition from two-phase co-current flow to counter-current flow.

Fig. 6 shows the liquid holdup for power law liquids as a function of the Lockhart-Martinelli parameter, $X^{2}$, in stratified flows. It is shown that $q$ has a minimal effect on $a$ in the range of relatively high $X^{2}$ values in a laminar-liquid and a turbulent-gas flow. For

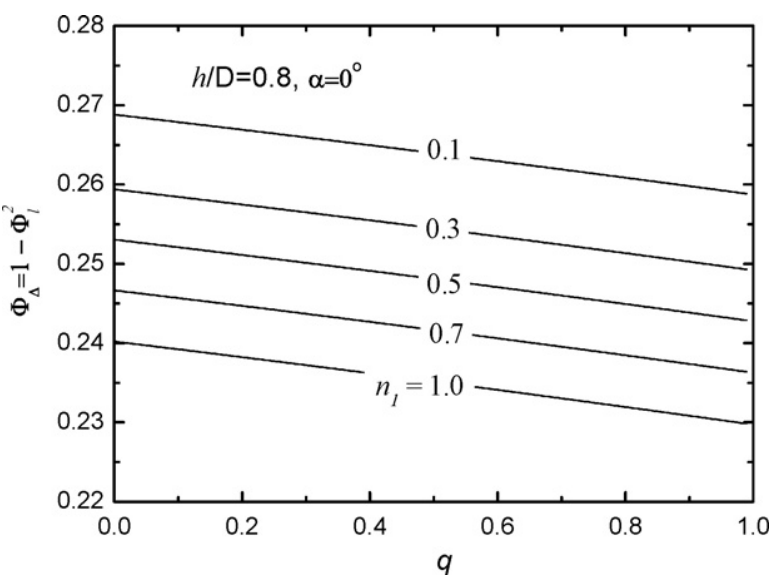

Fig. 4. The drag reduction ratio, $\Phi_{\Delta}$, as a function of the ratio of liquid flowrate to gas flowrate under constant $\tilde{h}=h / D$ in stratified horizontal flow. 

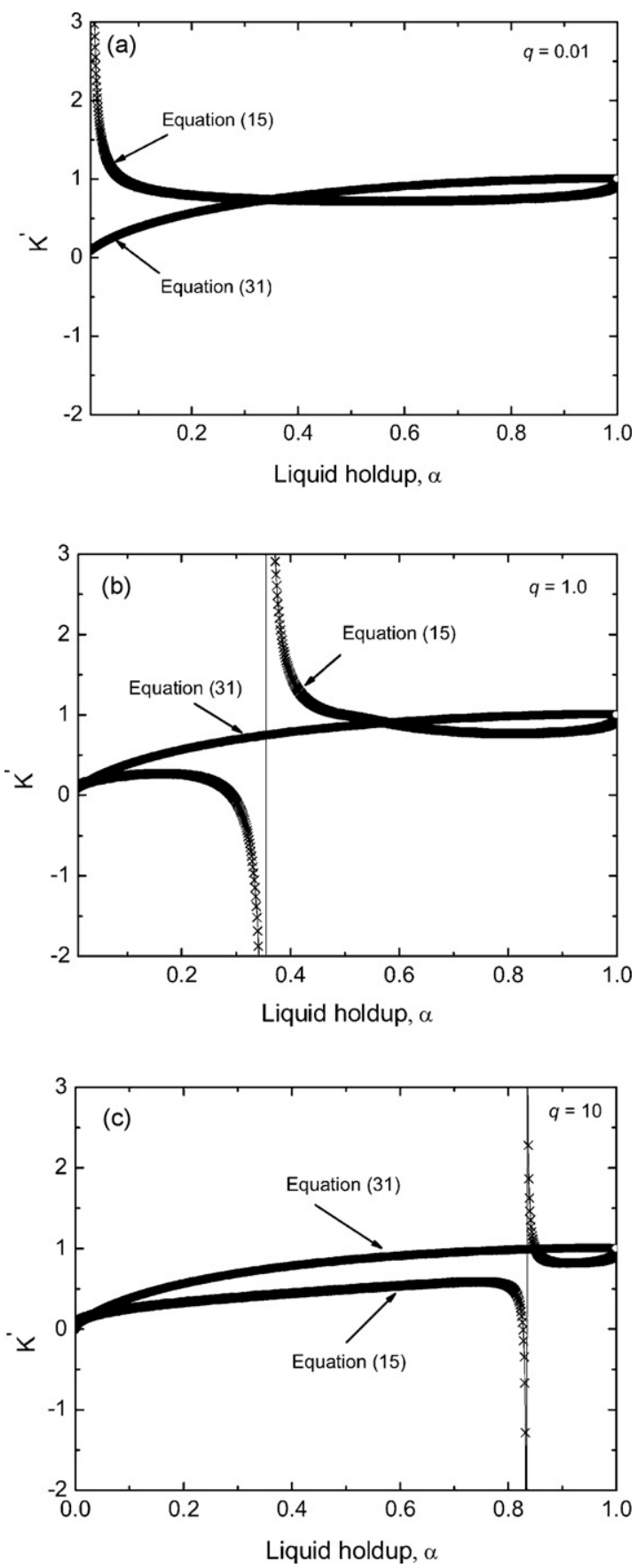

Fig. 5. Comparison between the theoretical method in this work and the Heywood and Charles model for predicting the effects of $K^{\prime}$ on the liquid holdup.

high $q$ values, the effect of $X^{2}$ on $\alpha$ is of minor importance and the reverse is true for low $q$ values. The effect of the dimensionless diameter $\left(\tilde{D}_{1}=D_{1} / D\right)$ on the dimensionless pressure drop $\left(\Phi_{1}^{2}\right)$ can be obtained by Eq. (14) for the stratified flow of two-phase. It can be seen in Fig. 7 that, for a low value $\tilde{D}_{1}$, the dimensionless diameter has a prominent influence on $\Phi_{1}^{2}$ and the influence become reduced gradually with $\tilde{D}_{1}$ increasing. Moreover, the lower the value of $n_{1}$ is, the smaller the value of $\Phi_{1}^{2}$ will be.

In order to validate the method of stratified flow, the experimental data are compared with the results predicted from Eqs. (11) and (12), as shown in Figs. 8 and 9. The results of these comparisons indicate good agreement for the liquid holdup data and

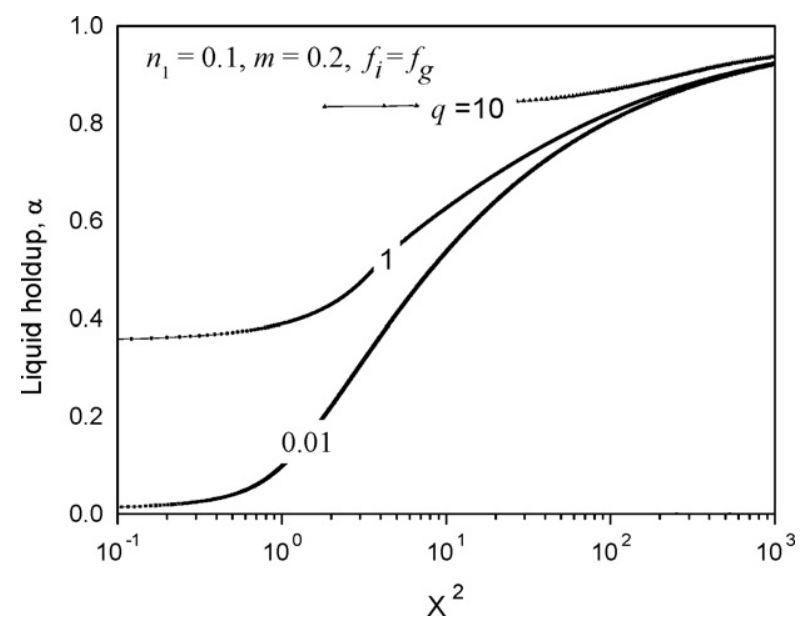

Fig. 6. The liquid holdup for power law liquids as a function of the Lockhart-Martinelli parameter, $X^{2}$, in horizontal stratified flow.

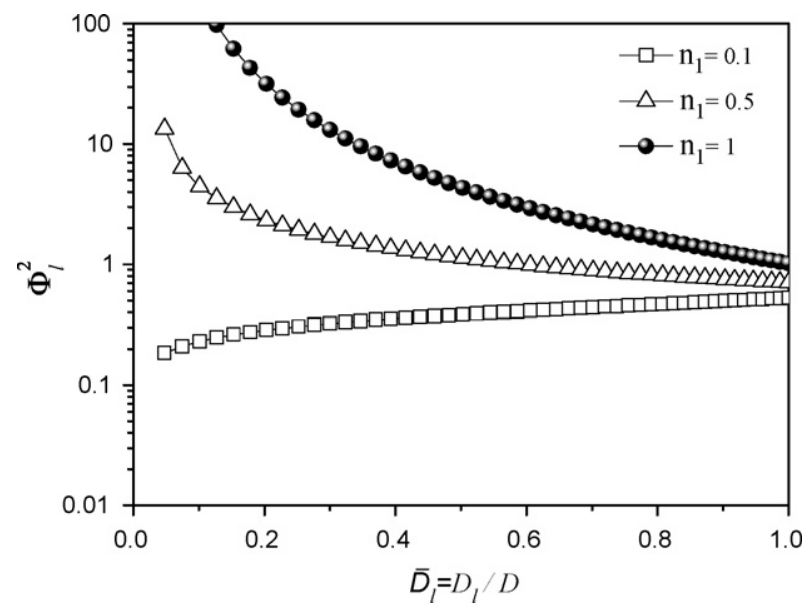

Fig. 7. The effect of the dimensionless diameter $\left(\tilde{D}_{1}=D_{1} / D\right)$ on the dimensionless pressure drop ( $\Phi_{1}^{2}$ ) for the stratified flow of two-phase.

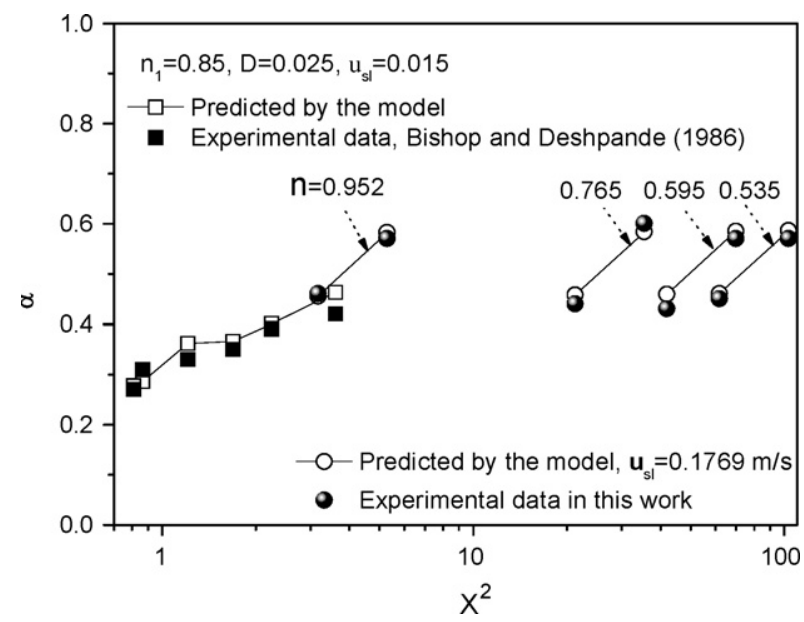

Fig. 8. Comparison of the theoretical predictions obtained from Eqs. (12) and (13) for the average liquid holdup with experimental data in this work and those in Bishop and Deshpande' work [7] in horizontal stratified flow regime. 


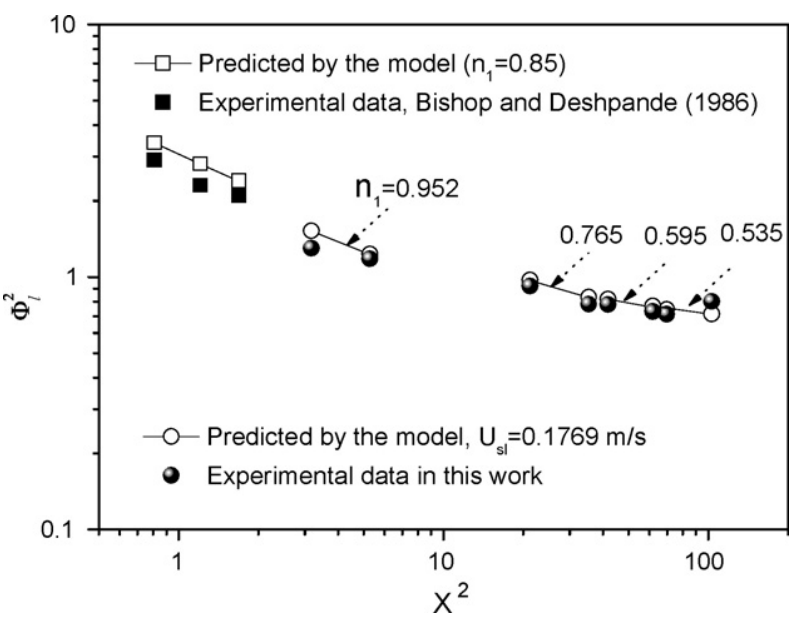

Fig. 9. Comparison of the theoretical predictions obtained from Eqs. (12) and (13) for the dimensionless pressure drop with experimental data in this work and those in Bishop and Deshpande' work [7] in horizontal stratified flow regime.

the dimensionless pressure drop. In Bishop and Deshpande's work, two-phase drag reduction cannot be achieved in stratified flow of non-Newtonian liquid-gas mixtures. They hypothesized that the drag reduction was restricted to those situations where streamline flow patterns existed at the head of an elongated bubble so that the drag reduction could not exist in liquid-gas stratified flow. However, in the present work, it can be seen in Figs. 3 and 9 that the drag reduction should occur over the large range of the liquid holdup when $n_{1}$ remains at the low value. The reason that the drag reduction is not observed may be due to the fact that the flow behaviour index of non-Newtonian material in their experiments is not low enough. ( $n_{1}=0.85$ in Bishop and Deshpande' work [7].)

\subsection{Drag reduction in slug flow}

For calculating the pressure drop of gas/Newtonian fluid in a horizontal slug flow, Orell [23] reformulated the simple submodel of Taitel and Barnea [18]. In the present study, we carried out a series of experiments to study the drag reduction by considering the Ostwald-de Waele power law model. In addition, a large set of available experimental data over a wide range of operating conditions and pipe diameters in the literature was used to validate the developed model.

A typical plot of the variation of pressure drop with gas flowrate, $Q_{g}$, at constant liquid flow rate, $Q_{\mathrm{l}}$, for different CMC solutions is shown in Fig. 10. It can be seen that, for air/CMC-3 solution and air/CMC-4 solution, the mixture of gas/non-Newtonian liquid in a pipe enables a significant reduction in the average pressure gradient to be reached. Fig. 11 illustrates the effects of liquid flow rate on the drag reduction ratio for air/CMC-4 solution flow. At lower gas flow rate within the range of $1.25 \mathrm{~m}^{3} / \mathrm{h} \leq Q_{\mathrm{g}} \leq 10.0 \mathrm{~m}^{3} / \mathrm{h}, \Phi_{\Delta}$ increases monotonically with the gas flow rate increasing. However, the drag reduction ratio tends to reach constant values when gas flow rate is further increased. The reason can be explained by the fact that, supposing the no slip velocity between the gas and liquid phases and the homogeneous flow, the Reynolds number of two-phase can be obtained via Eq. (11):

$R e_{\mathrm{MR}}=\frac{D u_{\mathrm{m}} \rho_{\mathrm{m}}}{\mu_{\mathrm{eff}}}$

where $u_{\mathrm{m}}=u_{\mathrm{sg}}+u_{\mathrm{sl}}$ is the mixture velocity, $\mu_{\mathrm{eff}}=$ $D^{1-n_{1}} 8^{n_{1}-1} K\left(u_{\mathrm{sg}}+u_{\mathrm{sl}}\right)^{n_{1}-1}\left(n_{1} \leq 1\right)$ is defined as the "effective viscosity". It can be observed from Eq. (32) that, for a fluid of given rheology (coefficient $n_{1}$ and $m_{1}$ ), increasing the superficial gas

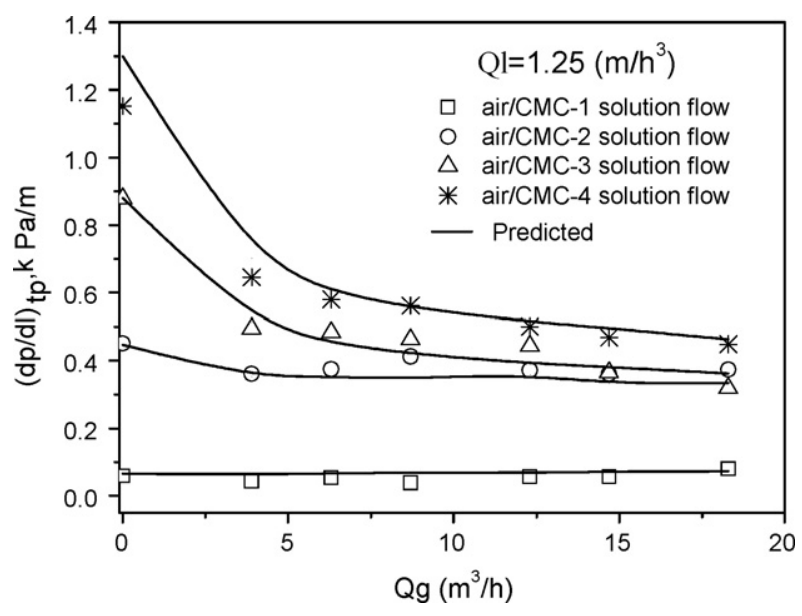

Fig. 10. Experimental pressured drop measurements in the fully developed slug flow conducted in pipelines with different polymer solutions at constant liquid phase flow rate.

velocity will reduce the effective viscosity so that the frictional pressure gradient is decreased. However, the gas will always disturb the flow and there will be additional pressure losses in the mixture of two-phase flow so that two-phase pressure gradient is augmented. Therefore, the drag reduction ratio, $\Phi_{\Delta}$, might show different tendencies when the gas flow rate increasing, as shown in Fig. 11. Moreover, the influence of pipe diameter on the pressure drop can also be studied from Eq. (32). When input fluids flow rates are fixed, the Reynolds number of two-phase is increased with the increase of the diameter pipe so that the friction factor ( $f$ ) should be decreased. Thus, it can be seen from Eq. (33) that, with the diameter pipe increased, two-phase pressure drop will be decreased.

$\Delta P_{\mathrm{tp}}=\frac{2 f \rho_{\mathrm{m}} u_{\mathrm{m}}^{2}}{D}$

The ratio of the liquid slug zone of length to the slug unit of length, $T$, can be calculated using Eq. (25), which plays an important role in calculating the pressure gradient of gas-liquid two-phase flow [23]. It can been found in Section 2.2 that the calculations have been performed depending on the conditions of a Newtonian fluid, not those of a non-Newtonian fluid, because for the mixture flow of gas/non-Newtonian fluid, no reliable methods exist for the calculation of the translation velocity, $u_{\mathrm{t}}$, nor for the liquid holdup within the liquid slug, $\alpha_{\mathrm{s}}$. However, for predicting the average liquid

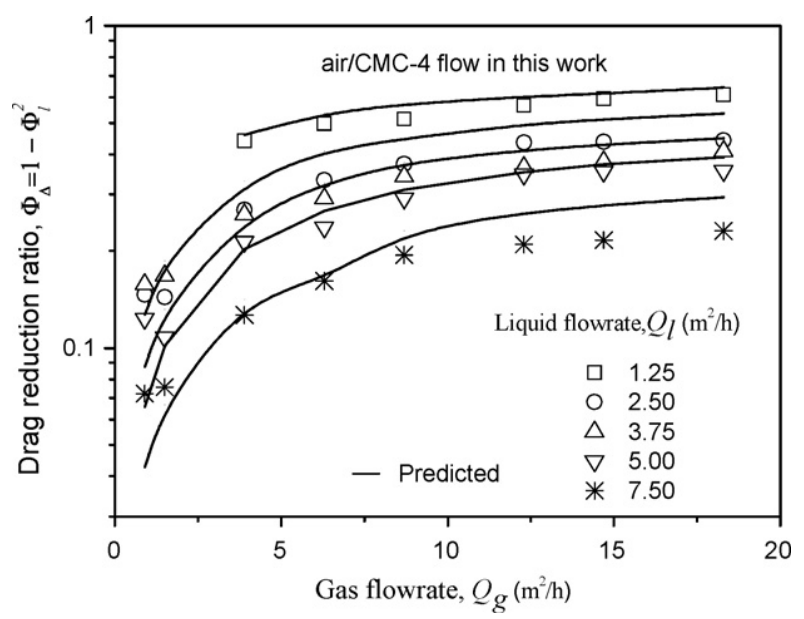

Fig. 11. Effects of fluid flow rate on the drag reduction ratio for air/CMC-4 slug flow. 


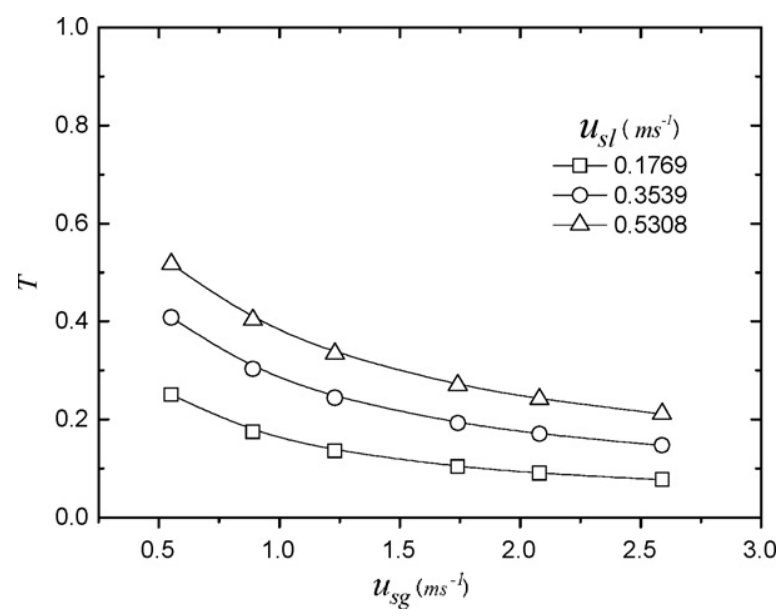

Fig. 12. Effects of superficial velocities on the ratio of the liquid slug zone of length to the slug unit of length for the constant superficial liquid velocity.

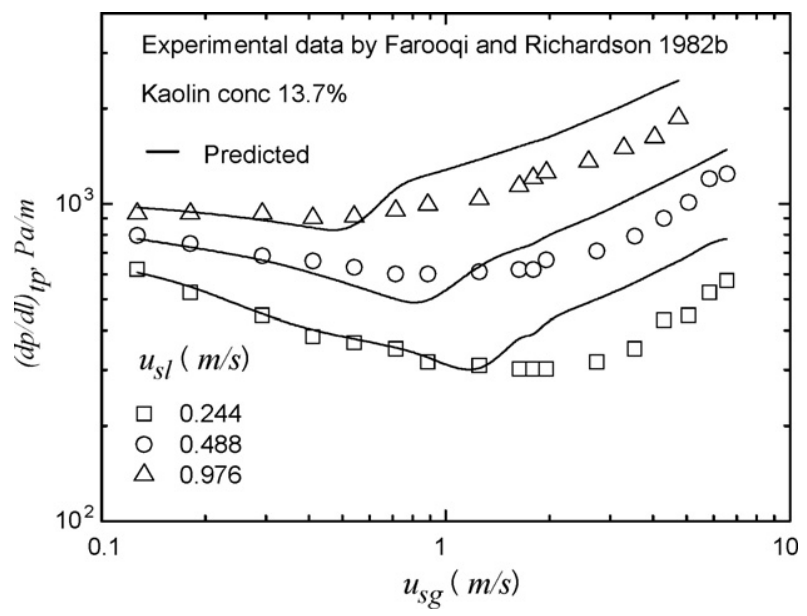

Fig. 13. Comparison of the predicted pressure gradient with the data of Farooqi and Richardson [9] for air and kaolin suspensions slug flowing in a pipe of $0.0417 \mathrm{~m}$ in diameter (the flow behaviour index, $n=0.175$ ).

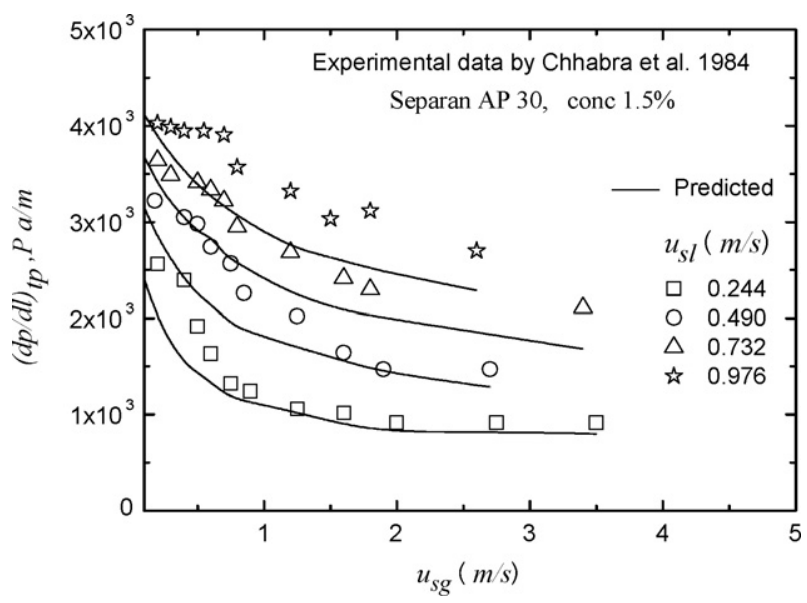

Fig. 14. Comparison of the predicted pressure gradient with the data of Chhabra et al. [14] for Separan AP 30 flowing in a pipe of $0.0417 \mathrm{~m}$ in diameter (the flow index, $n=0.28)$.
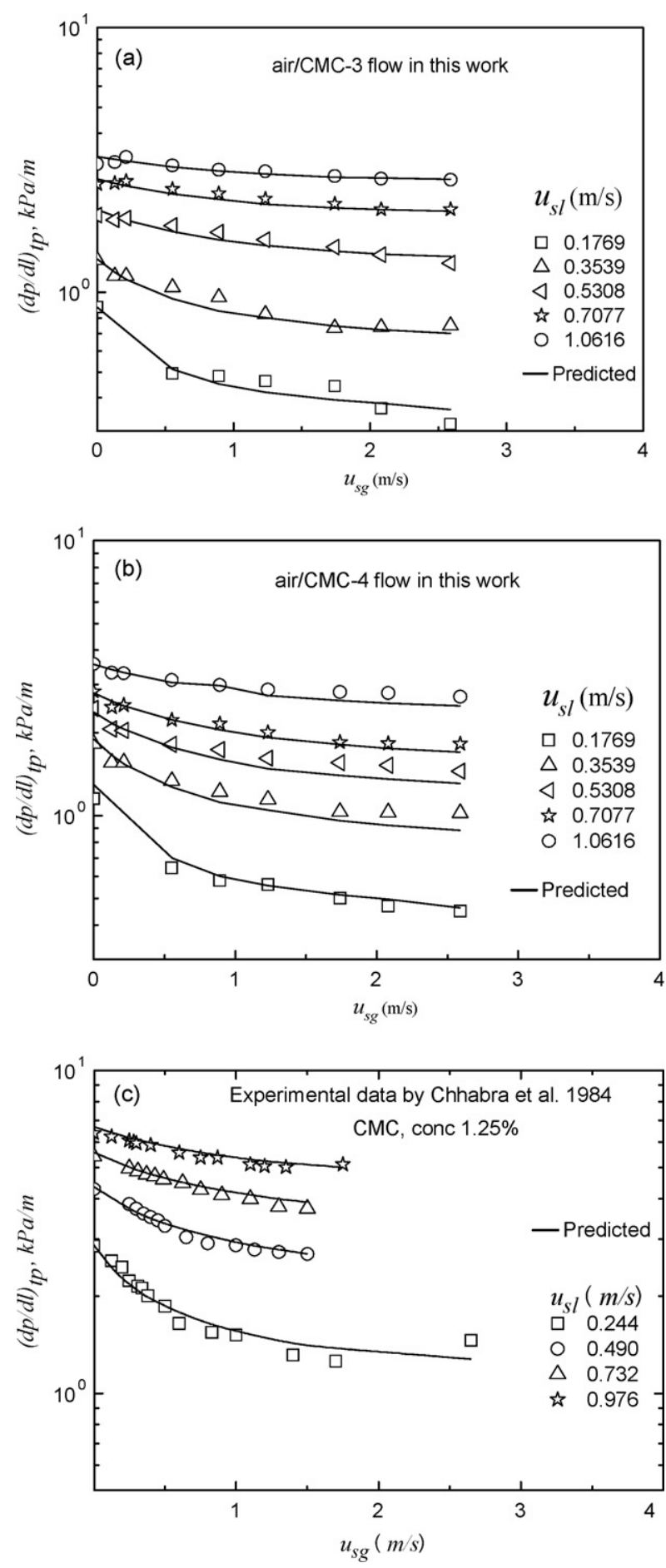

Fig. 15. Comparison of the predicted pressure gradient with experimental data of Chhabra et al. [14] and the present work for air/CMC solutions flowing in a pipe of $0.0417 \mathrm{~m}$ i.d. and of $0.05 \mathrm{~m}$ i.d., respectively (a) the flow index, $n=0.535$; (b) the flow index, $n=0.595$; (c) the flow index, $n=0.580$.

holdup, the model can describe the majority of the experimental data within $20 \%$ [12]. Fig. 12 shows the effects of superficial velocities on $T$ for the constant $u_{\mathrm{sl}}$. It is illustrated clearly that $T$ decreases with superficial gas velocity increasing and increases with superficial liquid velocity increasing for a given $u_{\mathrm{sg}}$.

To calculate exactly the drag reduction ratio, the pressure gradient of two-phase flow calculated by the model has to be validated firstly. Fig. 13 displays the comparison of the predicted pressure 
gradient with the data of Farooqi and Richardson [9] for air and kaolin suspensions slug flowing. At low superficial gas velocities the pressure drop decreases as $u_{\mathrm{sg}}$ is increased. It reaches to a minimum value at the critical velocity for the transition from laminar to turbulent flow. Past this velocity, the pressure gradient increases steadily. Furthermore, with further increasing the superficial liquid velocity at any given $u_{\text {sg }}$, both theoretical and experimental pressure drops become higher over the entire range of the tested data. A very good agreement is obtained between the theoretical and experimental pressure gradients in the superficial gas velocity range of $0-1.0 \mathrm{~m} / \mathrm{s}$. However, the data in the high gas velocity range of $1.0-6.5 \mathrm{~m} / \mathrm{s}$ are over-predicted by the model. It should be noted that the two-phase flow pattern is difficult to keep a shape of slug when superficial gas velocity is higher than $3 \mathrm{~m} / \mathrm{s}$ [24] shows that the flow of gas-liquid should be in the form of semi-slug flow under this condition. Thus, although the use of a slug model for all intermittent flow regimes is questionable, in the whole range both the theoretical curves and the experimental data exhibit the same trend and the overall agreement of predicted values with experimental data is good.

Fig. 14 shows that the comparison between the predicted pressure gradient and experimental data of Chhabra et al. [14] for air and Separan AP-30 flowing in a pipe of $0.0417 \mathrm{~m}$ in diameter. It can be found that the model under predicts the data. The experimental pressure drops increase rather unevenly and are scattered compared to the calculated theoretical values. The discrepancy between the theoretical and experimental values may be due to the fact that, in additions to shear-thinning characteristics, aqueous solutions of polyacrylamide (Separan AP-30) has finite normal stress differences in steady shearing conditions.

Fig. 15 compares the predicted pressure gradient with experimental data of Chhabra et al. [14] and the present work for air/CMC solutions flowing in a pipe of $0.0417 \mathrm{~m}$ i.d. and of $0.05 \mathrm{~m}$ i.d., respectively. An excellent agreement is obtained between theory and data. The pressure gradient predicted by the model for gas/power-law fluid slug flow, as well as the experimental data, indicate that the drag reduction by gas injection is more prominent with low superficial gas velocities.

Finally, the proposed method for slug flow has been checked by plotting the experimental values of the dimensionless pressure drop vs. the predicted ones calculated from Eq. (26). As Fig. 16 shows, the use of Eq. (26) allows a good prediction of the dimen-

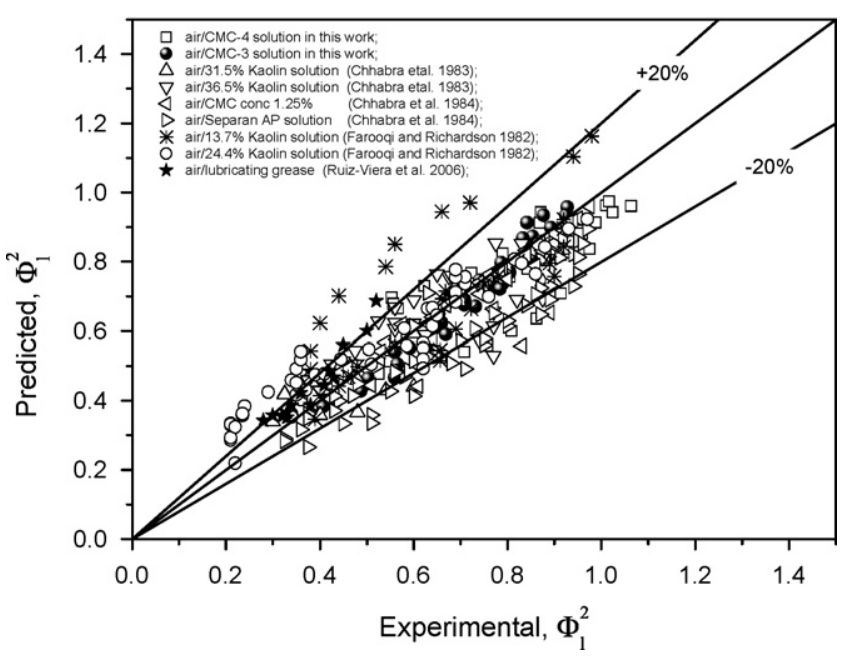

Fig. 16. Compared between experimental and theoretical obtained from Eq. (26), values of the dimensionless pressure drop, for gas/non-Newtonian fluid flow studied in this work and for others systems reported in the literature. sionless pressure drop for the gas/non-Newtonian power-law fluid mixture flow. Most of the experimental values are well inside the $20 \%$ deviation region using 340 experimental data point collected from different Refs. $[9,11,13,14]$ including the smooth and rough pipes.

\section{Conclusions}

An experimental and theoretical study of gas/non-Newtonian fluid flow through the horizontal pipes has been conducted. Special attention is given to study the drag reduction by gas injection for power-law fluid flow in stratified and slug flow regimes. The method for predicting the maximum drag reduction ratio in stratified flow regime is presented. The results show that, for turbulent gas-laminar liquid stratified flow, the drag reduction by gas injection for Newtonian fluid is more effective than that for shearshinning fluid when the dimensionless liquid height remains in the area of high value. Furthermore, the drag reduction should occur over the large range of the liquid holdup when the flow behaviour index remains at the low value. The method for predicting the gas-liquid stratified is validated by the experimental data. Results indicate good agreement for the liquid holdup data and the dimensionless pressure drop.

The pressure gradient model for a gas/Newtonian liquid slug flow is extended to liquids possessing the Ostwald-de Waele power law model for studying the drag reduction in slug flow regime. The proposed models are validated against a large set of available experimental data over a wide range of operating conditions, fluid characteristics and pipe diameters. A good agreement is obtained between the predicted and experimental results. The dimensionless pressure drop predicted is well inside the $20 \%$ deviation region for most of the experimental data. These results substantiate the general validity of the model presented for gas/non-Newtonian two-phase slug flows.

In summary, as it appears from the results predicted, the accuracy of the suggested models is good and sufficient enough to be practically applied in industry. In practical application, once that the fluid properties $\left(n_{1}\right.$ and $\left.m_{1}\right)$, pipe diameter and input fluids flow rates have been obtained, the two-phase pressure drop and the drag reduction ratio can be calculated using these equations. These are benefit to design the long pipelines and pumps from an economic viewpoint.

\section{Acknowledgments}

The authors gratefully acknowledge that the work presented here was financially supported by both the National Natural Science Foundation of China (No. 10572143) and the Eleventh-Five-Year Key Project of Chinese Academy of Sciences (No. KJCX2-YW-L02).

\section{References}

[1] P.D. Mansfield, C.J. Lawrence, G.F. Hewitt, Drag reduction with additives in multiphase flow: a literature survey, Multiphase Sci. Technol. 11 (1999) 197-221.

[2] A. Al-Sarkhi, T.J. Hanratty, Effect of drag-reducing polymers on annular gas-liquid flow in horizontal pipe, Int. J. Multiphase Flow 27 (2001) 1151-1162.

[3] A. Soleimani, A. Al-Sarkhi, T.J. Hanratty, Effect of drag-reducing polymers on pseudo-slugs-interfacial drag and transition to slug flow, Int. J. Multiphase Flow 28 (2002) 1911-1927.

[4] S. Baik, T.J. Hanratty, Effects of a drag-reducing polymer on stratified gas-liquid flow in a large diameter horizontal pipe, Int. J. Multiphase flow 29 (2003) 1749-1757.

[5] D. Mowla, A. Naderi, Experimental study of drag reduction by a polymeric additive in slug two-phase flow of crude oil and air in horizontal pipes, Chem. Eng. Sci. 61 (2006) 1549-1554

[6] N. Heywood, M.E. Charles, The stratified flow of gas and non-Newtonian liquid in horizontal pipes, Int. J. Multiphase Flow 5 (1979) 341-352. 
[7] A.A. Bishop, S.D. Deshpande, Non-Newtonian liquid-air stratified flow through horizontal tubes-II, Int. J. Multiphase Flow 12 (1986) 977-996.

[8] S.I. Farooqi, N.I. Heywood, J.F. Richardson, Drag reduction by air injection for suspension flow in a horizontal pipeline, Trans. IChemE. 58 (1980) 16-27.

[9] S.I. Farooqi, J.F. Richardson, Horizontal flow of air and liquid (Newtonian and non-Newtonian) in a smooth pipe. II. Average pressure drop, Trans. IChemE. 60 (1982) 323-333.

[10] M. Dziubinski, A general correlation for the two-phase pressure drop in intermittent flow of gas and non-Newtonian liquid mixtures in a pipe, Trans. Chem. Eng. Res. Des. 73 (1995) 528-533.

[11] M.J. Ruiz-Viera, M.A. Delgado, J.M. France, M.C. Sánchez, C. Gallegos, On the drag reduction for the two-phase horizontal pipe flow of highly viscous nonNewtonian liquid/air mixtures: case of lubricating grease, Int. J. Multiphase Flow 32 (2006) 232-247.

[12] J. Xu, Y. Wu, Z. Shi, L. Lao, D. Li, Studies on two-phase co-current air/nonNewtonian shear-thinning fluid flows in inclined smooth pipes, Int. J. Multiphase Flow 33 (2007) 948-969.

[13] R.P. Chhabra, S.I. Farooqi, J.F. Richardson, A.P. Wardle, Co-current flow of air and shear-thinning suspensions in pipes of large diameter, Chem. Eng. Res. Des. 61 (1983) 56-61.

[14] R.P. Chhabra, S.I. Farooqi, J.F. Richardson, Isothermal two-phase of air and aqueous polymer solutions in a smooth horizontal pipe, Chem. Eng. Res. Des. 62 (1984) 22-31.
[15] Y. Taitel, A.E. Dukler, A model for prediction flow regime transition in horizontal and near horizontal gas-liquid, AICHE J. 22 (1976) 47-55.

[16] A.E. Duker, M.G. Hubbard, A model for gas-liquid slug flow in horizontal and near horizontal tubes, Ind. Eng. Chem. Fundam. 14 (1976) 337-347.

[17] R.W. Lockhart, R.C. Martinelli, Proposed correlation of data for isothermal two-phase, two-component flow in pipes, Chem. Eng. Prog. 45 (1949) 39-48.

[18] Y. Taitel, D. Barnea, A consistent approach for calculating pressure drop in inclined slug flow, Chem. Eng. Sci. 45 (1990) 1199-1206.

[19] K. Bendiksen, An experimental investigation of the motion of long bubbles in inclined tubes, Int. J. Multiphase Flow 10 (1984) 467-483.

[20] G.A. Gregory, M.K. Nicholson, K. Aziz, Correlation of the liquid volume fraction in the slug for horizontal gas-liquid slug flow, Int. J. Multiphase Flow 4 (1978) 33-39.

[21] O.J. Nydal, S. Pintus, P. Andreussi, Statistical characterization of slug flow in horizontal pipes, Int. J. Multiphase Flow 18 (1992) 439-453.

[22] P. Andreussi, K.H. Bendikcen, O.J. Nydal, Void distribution in slug flow, Int. J. Multiphase Flow 18 (1993) 817-828.

[23] A. Orell, Experimental validation of a simple model for gas-liquid slug flow in horizontal pipes, Chem. Eng. Sci. 60 (2005) 1371-1381.

[24] G.F. Hewitt, Liquid-gas systems, in: G. Hetsroni (Ed.), Handbook of Multiphase Systems, McGraw-Hill, New York, 1982. 